\title{
BIOTECHNOLOGICAL PRODUCTION OF CITRIC ACID
}

\section{Belén Max ${ }^{1}$; José Manuel Salgado ${ }^{1}$; Noelia Rodríguez ${ }^{1}$; Sandra Cortés ${ }^{1}$; Attilio Converti²; José Manuel Domínguez ${ }^{1, *}$}

${ }^{1}$ Department of Chemical Engineering, Sciences Faculty, University of Vigo (Campus Ourense), As Lagoas s/n, 32004 Ourense, Spain; ${ }^{1}$ Laboratory of Agro-food Biotechnology, CITI-Tecnópole, Parque Tecnológico de Galicia, San Cibrao das Viñas, Ourense, Spain; ${ }^{2}$ Department of Chemical and Process Engineering, University of Genoa, Via Opera Pia 15, 16145 Genoa, Italy.

Submitted: April 16, 2010; Approved: May 24, 2010.

\begin{abstract}
This work provides a review about the biotechnological production of citric acid starting from the physicochemical properties and industrial applications, mainly in the food and pharmaceutical sectors. Several factors affecting citric acid fermentation are discussed, including carbon source, nitrogen and phosphate limitations, $\mathrm{pH}$ of culture medium, aeration, trace elements and morphology of the fungus. Special attention is paid to the fundamentals of biochemistry and accumulation of citric acid. Technologies employed at industrial scale such as surface or submerged cultures, mainly employing Aspergillus niger, and processes carried out with Yarrowia lipolytica, as well as the technology for recovering the product are also described. Finally, this review summarizes the use of orange peels and other by-products as feedstocks for the bioproduction of citric acid.
\end{abstract}

Key words: citric acid, fermentation, review, Aspergillus niger

\section{INTRODUCTION}

Citric acid (2-hydroxy-propane-1,2,3-tricarboxylic acid) derives its name from the Latin word citrus, a tree whose fruit is like the lemon. Citric acid is a tricarboxylic acid (Figure 1) with a molecular weight of $210.14 \mathrm{~g} / \mathrm{mol}$, which contains three carboxylic functional groups with three different values of $\mathrm{p} K_{\mathrm{a}}$ (3.1, 4.7, and 6.4). It is a primary metabolic product formed in the tricarboxylic acid (or Krebs) cycle and is found in small quantities in virtually all plants and animals, being isolated from lemon juice in 1784 .

Citric acid was first commercially-produced in England around 1826 from imported Italian lemons (lemons contain 7$9 \%$ citric acid). Lemon juice remained the commercial source of citric acid until 1919, when the first industrial process using Aspergillus niger started in Belgium. Currently, the extraction of citric acid is limited to some small factories in Mexico and Africa.

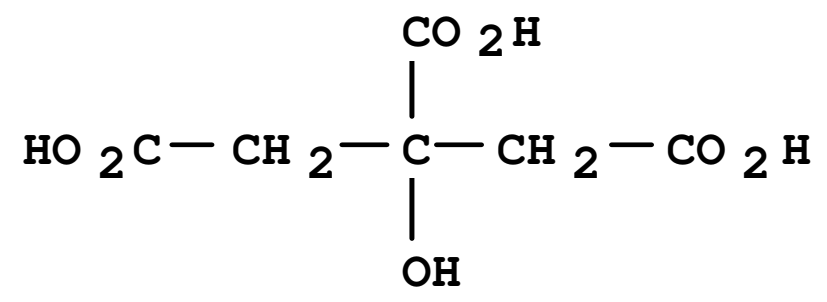

Figure 1. Chemical structure of citric acid. 
Citric acid was synthesized from glycerol by Grimoux and Adams (21) and later from symmetrical dicloroacetone. Other routes have been published from various synthetic materials since then, but chemical methods have so far proved uncompetitive.

Wehmer (106) was the first to demonstrate that Citromyces (now Penicillium) accumulated citric acid in a medium containing sugar and inorganic salts. Since then, many organisms have been found to accumulate citric acid: A. niger, Aspergillus awamori, Aspergillus nidulans, Aspergillus fonsecaeus, Aspergillus luchensis, Aspergillus phoenicus, Aspergillus wentii, Aspergillus saitoi, Aspergillus flavus, Absidia sp., Acremonium sp., Botrytis sp., Eupenicillium sp., Mucor piriformis, Penicillium janthinellum, Penicillium restrictum, Talaromyces sp., Trichoderma viride and Ustulina vulgaris (73).

Currie (15) found that some strains of A. niger were able to grow in a medium containing sugars and salts at an initial $\mathrm{pH}$ of 2.5-3.5. Throughout their growth, these strains excreted large amounts of citric acid, which established the basis for industrial production.

Besides fungi, it is known that several yeasts produce citric acid from $n$-alkanes and carbohydrates (63), especially species belonging to the genera Candida, Hansenula, Pichia, Debaromyces, Torula, Torulopsis, Kloekera, Saccharomyces, Zygosaccharomyces and Yarrowia. During the '60s and '70s oil was cheap, and citric acid was produced industrially from this source by Candida sp., including $C$. tropicalis, C. catenula, $C$. guilliermondii and C. intermediate (73). Today, this production is not economical. As a disadvantage, the fermentation by yeasts led to the formation of large quantities of isocitric acid as an unwanted byproduct, so mutant strains with low aconitase activity should be used.

Although many microorganisms can be employed to produce citric acid, A. niger is still the main industrial producer. In fact, specific strains that are able to overproduce citric acid in different types of fermentation processes have been developed. The theoretical yield is $112 \mathrm{~g}$ of anhydrous citric acid per $100 \mathrm{~g}$ of sucrose. However, in practice, due to losses during trophophase, the yield of citric acid from these strains often does not exceed $70 \%$ of the theoretical yield on carbon source. Despite a long and successful history of producing citric acid, there is not unanimous explanation of the biochemical basis of the process.

\section{FACTORS AFFECTING CITRIC ACID FERMENTATION}

The conditions for citric acid fermentation were established during the '30s and '40s when the effects of various components of the fermentation media were evaluated.

The accumulation of citric acid is strongly influenced by the composition of the medium, especially in submerged fermentation processes. However, with the exception of early studies by Currie (15), there were no other systematic studies on the composition of the medium until the 40s $(92,93)$. These authors developed a medium that was the basis for further research on the production of citric acid. It was shown that the factors mainly affecting the citric fermentation are the type and concentration of carbon source, nitrogen and phosphate limitation, $\mathrm{pH}$, aeration, oligoelements concentration, and morphology of the producing microorganism. Certain nutrients have to be in excess (such as sugars, protons or oxygen), other at limiting levels (such as nitrogen and phosphate) and others below well-established threshold values (such as trace metals, particularly manganese).

\section{Carbon source}

The carbon source for citric fermentation has been the subject of many studies, especially regarding the use of polysaccharides. In general, only the sugars that are quickly assimilated by the microorganism allow high final yield of citric acid (62).

Polysaccharides are a useful raw material for fermentation only if the microorganism possesses hydrolytic enzymes highly effective at the low $\mathrm{pH}$ values required for fermentation. In general, sucrose is preferable to glucose $(24,30,42,110)$, as $A$. niger has an extracellular mycelium-bound invertase that is 
active at low $\mathrm{pH}$.

The most widely used carbon sources in industrial fermentations are glucose syrups from starch hydrolysis, sugar beet molasses and low quality-sugarcane byproducts that, in general, are contaminated by high levels of cations from previous processes. Cations usually come from insoluble residues formed by precipitation with potassium ferrocyanide. Due to the complexity of these pretreatments, a lot of research has been conducted using refined sugars, mainly glucose or sucrose.

The concentration of carbon source is also crucial for citric fermentation. The final yield of citric acid increases with initial sugar concentration in batch processes or glucose feeding rate in chemostat, while the specific growth rate has an opposite behaviour $(29,76,79,80,92,93,110)$. The highest productivities are usually achieved using 14-22\% sugar, because such high concentrations of the carbon source lead to suppression of $\alpha$-ketoglutarate dehydrogenase (30). On the other hand, at low glucose levels the size of the mycelium is reduced, and its shape is also affected $(76,79,80)$.

\section{Nitrogen and phosphate limitations}

Some complex media (such as molasses) are rich in nitrogen and rarely need to be supplemented with a nitrogen source. The highly-pure media used in laboratory scaleresearch are usually supplemented with ammonium salts, particularly ammonium nitrate and sulfate, which in turn leads to a decrease in $\mathrm{pH}$ that favors fermentation (62). Other sources of nitrogen such as urea and yeast/malt extract have also been employed successfully (110).

Conflicting reports have also been cited regarding the effects of nitrogen and phosphate limitation. According to Shu and Johnson $(92,93)$, phosphate needs not be limiting for citric acid production; however, when metal levels are not limiting, additional phosphate leads to secondary reactions and promotes biomass growth $(76,79,80)$. However, Kubicek and Rohr (40) demonstrated that citric acid accumulated when phosphate was limiting, even when nitrogen was not. Instead, Kristiansen and Sinclair (37), using a continuous culture, came to the conclusion that the limitation by nitrogen is essential for the production of citric acid.

\section{pH of culture medium}

The $\mathrm{pH}$ of the medium is important in two stages of the process. All fermentations start from spores and their germination requires $\mathrm{pH}>5$. The absorption of ammonia by germinating spores causes release of protons, thus lowering the $\mathrm{pH}$ and improving the production of citric acid. The low $\mathrm{pH}$ value during the production phase $(\mathrm{pH} \leq 2)$ reduces the risk of contamination by other microorganisms and inhibits the production of unwanted organic acids (gluconic and oxalic acids), which makes the product recovery easier.

\section{Aeration}

Industrial producers of citric acid have long known that variations in the rate of aeration can have a detrimental effect on performance. If the aeration rate is too high, the partial pressure of dissolved $\mathrm{CO}_{2}$ in the broth may be too low. Carbon dioxide is important as a substrate for pyruvate carboxylase that replenishes the supply of oxaloacetate for citrate synthase. Sufficient $\mathrm{CO}_{2}$ is produced by the reaction catalyzed by pyruvate decarboxylase, but excessive aeration leads to some losses. On the contrary, high levels of $\mathrm{CO}_{2}$ in the gas are detrimental for the final concentrations of citrate and biomass (65). The effect of dissolved $\mathrm{O}_{2}$ has been studied in some detail. Even short periods of reduced $\mathrm{O}_{2}$ tension cause irreversible changes in the citric acid productivity (44).

\section{Trace elements}

A. niger requires certain trace metals for growth (62). However, a limitation by other trace elements is necessary for citric acid production $(92,93)$, especially in the submerged fermentation. The metals that should be in limiting concentrations are $\mathrm{Zn}, \mathrm{Mn}, \mathrm{Fe}, \mathrm{Cu}$ and heavy metals.

Shu and Johnson (92) demonstrated that the optimal levels of $\mathrm{Zn}$ and $\mathrm{Fe}$ are 0.3 and 1.3 ppm, respectively. Whereas Clark et al. (11) observed that Mn concentrations as low as $3 \mathrm{mg} / \mathrm{l}$ drastically reduced the citric acid yield, Mattey and Bowes (64) 
reported that the addition of $10 \mathrm{mg} / 1 \mathrm{Mn}^{2+}$ leads to a reduction in citric acid accumulation by $50 \%$. Researches by Clark et al. (11) and Kisser et al. (35) confirmed the regulatory role of $\mathrm{Mn}^{2+}$ ions. The anabolism of $A$. niger is affected by manganese deficiency and/or limitation by nitrogen and phosphate. The breakdown of proteins under $\mathrm{Mn}$ deficiency results in high intracellular concentration of ammonium, which contrasts the citric acid inhibition of phosphofructokinase and hence glycolysis. Moreover, the combination of high concentrations of glucose and ammonium represses the synthesis of $\alpha$ ketoglutarate dehydrogenase, hence inhibiting the catabolism of citric acid in the Krebs cycle and favoring its overproduction.

Manganese has also been proven important in many cell functions, particularly in the cell wall synthesis, sporulation and production of secondary metabolites (93). Therefore, great care must be taken when choosing the ingredients of the medium, including the bioreactor construction materials, to ensure that traces of manganese do not reduce the yield of fermentation.

\section{Morphology of the fungus}

The relationship between morphology of the fungus and productivity in submerged fermentations has been established long time ago. Despite disagreement on whether pellets or filamentous forms are more convenient for citric acid production, in all cases, the mycelium of acidogenic A. niger contains branches of short hyphae with swollen tips (94).

In submerged cultures, the morphology of fungi varies between pellets and free filaments, depending on growth conditions and genotype. The discussion of the factors influencing the morphology of A. niger in submerged cultures has to distinguish between macro and micro-morphology. Contrarily to Moyer (68), Snell and Schweiger (94) and Takahashi et al. (99) reported that citric acid production requires the formation of compact aggregates or pellets $(<0.5$ $\mathrm{mm}$ in diameter). Image analysis studies showed that, under appropriate conditions, yields exceed $85 \%$ when the macromorphological form is constituted by stable particles of intertwined filamentous around a small nucleus, while the micro-morphology is characterized by branches of short hyphae with swollen tips $(76,7778,79,80)$.

The main factors affecting the morphology of A. niger in submerged cultures and then influence the process performance are the agitation intensity, medium $\mathrm{pH}$, growth rate, nutritional factors and inoculum type and concentration.

Although intense agitation leads to the development of short, thick and highly branched filaments, excess shear stress can cause fragmentation of filaments, and the new fragments generated give rise to new filaments overproducing citric acid (80). The preferred morphology (i.e., small aggregates of short filaments) associated with an increase in production was obtained at $\mathrm{pH}$ values around $2.0 \pm 0.2$. At $\mathrm{pH} 1.6$, the morphological development was abnormal and production fell sharply, while at $\mathrm{pH} 3.0$ aggregates had longer perimeters and oxalic acid formation was observed (76).

Regarding those trace metals that greatly affect the fermentation, only the concentration of manganese has been shown to affect the morphology of A. niger. Manganese ions in concentration below $10^{-7} \mathrm{M}$ resulted in an abnormal morphological development (35), while the addition of $30 \mathrm{mg} / \mathrm{l}$ of $\mathrm{Mn}$ to a Mn-free medium led to morphological changes accompanied by a $20 \%$ reduction in citric acid yield (76). Thus, it is evident that optimum citric acid production is only possible within a strict $\mathrm{Mn}$ concentration range.

The spore inoculum level is another parameter that influences the citric acid fermentation. Papagianni and Mattey (75) found, through digital image analysis, a clear transition from pellets to dispersed forms of $A$. niger by varying the inoculum level from $10^{4}$ to $10^{9}$ spores $/ \mathrm{ml}$.

\section{BIOCHEMISTRY OF CITRIC ACID PRODUCTION}

To review the biochemistry of citric acid formation is an immense task. Shortly, it can be said that the overproduction of citric acid requires a unique combination of unusual nutritional conditions (excess of carbon source, hydrogen ions and dissolved oxygen, and suboptimal concentrations of certain 
trace metals and phosphate), which synergistically influence the fermentation performance (36).

According to Habison et al. (26) and Rohr and Kubicek (87), a deficiency of manganese, or phosphate and nitrogen limitation, inhibits the A. niger anabolism, and the resulting degradation of proteins leads to increased ammonium ion concentration. This increase is able to counterbalance the inhibition exerted by citric acid on phosphofructokinase (26), being a positive end-effector $(6,25)$. High concentrations of $\mathrm{NH}_{4}{ }^{+}$and glucose also repress the synthesis of $\alpha$-ketoglutarate dehydrogenase, inhibiting the citric acid catabolism via the Krebs cycle, leading to its accumulation (87). Therefore, one of the reasons for the accumulation of citric acid is the result of high speed flow of income and a reduction in outflow velocity (Figure 2). But, other observations appear to contradict these assumptions (81).

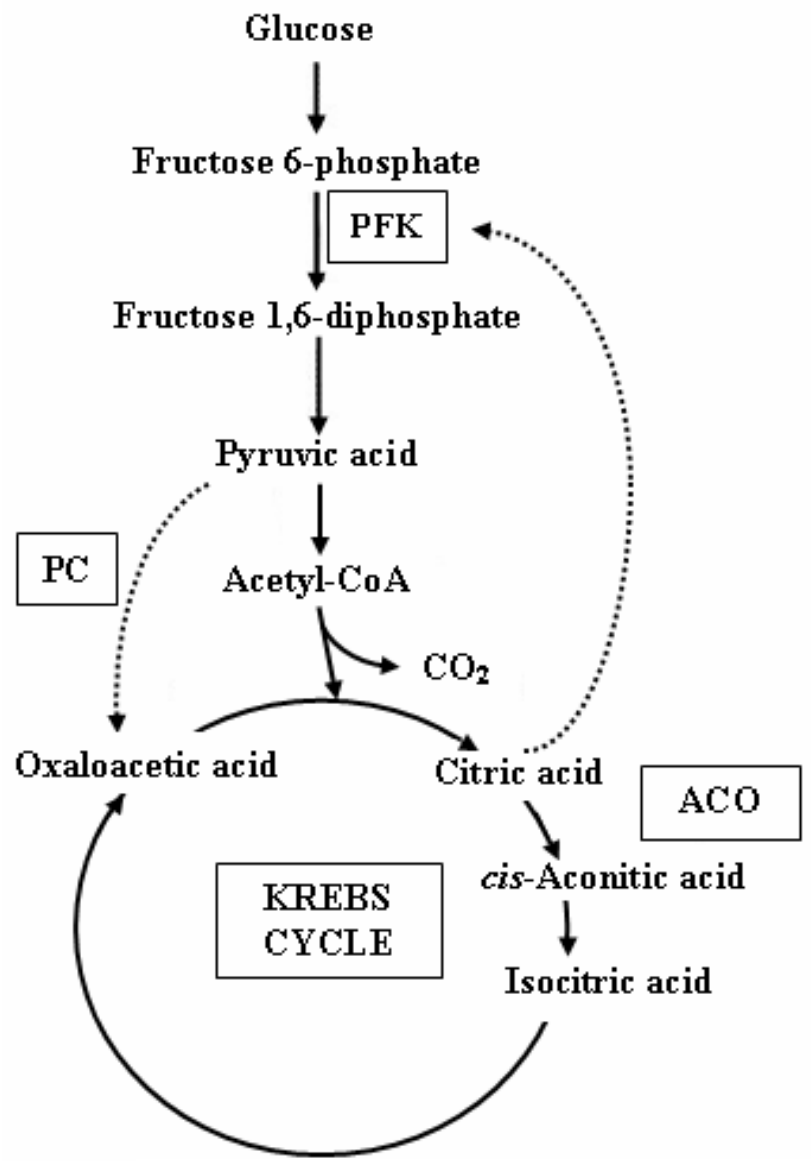

Figure 2. Schematic representation of the main metabolic reactions involved in the production of citric acid by $A$. niger (Manzoni, 2006). PFK = phosphofructokinase, $\mathrm{PC}=$ pyruvate carboxylase, $\mathrm{ACO}=$ aconitase.
Other smaller issues are of interest to other enzymes: invertase $(9,89)$, hexokinase $(91,97)$, glucose oxidase $(18,28$, 67, 86), phosphofructokinase $(26,32,46,55,62)$, other enzymes of the pentose phosphate pathway (56), pyruvate kinase $(16,17,66,90,100,101)$, and citrate synthase $(41,58)$.

An important aspect concerns the need that the Krebs cycle can be completed to support the continuous production of citric acid. To address the lack of cycle intermediates consequent to the metabolic dysfunction responsible for the accumulation of citric acid, pyruvic acid produced from glucose is not only decarboxylated to acetyl-CoA by the pyruvate dehydrogenase complex, but it is also partially carboxylated to oxaloacetic acid during the idiophase (45), by the action of pyruvate carboxylase $(8,13,19,107,108)$. This reaction, which requires ATP and is dependent on $\mathrm{K}^{+}$and $\mathrm{Mg}^{2+}$, is not the only anaplerotic reaction used to replenish the Krebs cycle. Depending on the organism, more oxaloacetic acid can be produced from phosphoenolpyruvic acid and $\mathrm{CO}_{2}$ by phosphoenolpyruvate carboxykinase, phosphoenolpyruvate carboxytransphosphorylase, and phosphoenolpyruvate carboxylase, and from pyruvic acid by the NADPH-dependent malic enzyme (60).

Finally, it must be remembered that breaking of isocitric acid by isocitrate lyase is the first reaction of glyoxylic acid cycle, a pathway that leads to the synthesis of L-malic acid from isocitric acid and acetyl-CoA, via oxalic acid, a toxic byproduct (69) that can accumulate under suboptimal conditions. Kubicek et al. (43) demonstrated that this pathway, which helps to restore the Krebs cycle intermediates, is poorly active from sugars, meanwhile isocitrate lyase and malate synthase, the second enzyme of the glyoxylic acid cycle, are induced when acetate or $n$-alkanes are used as carbon sources (60).

\section{ACCUMULATION OF CITRIC ACID}

It has been proposed that the accumulation of citric acid requires deactivation of the Krebs cycle enzymes responsible for its degradation, aconitase and/or isocitrate dehydrogenase. 
But there are evidences that during the production of citric acid, the Krebs cycle is active in the production of intermediates required for biomass formation $(3,32)$. Therefore, as stressed by Kubicek (39), citric acid accumulation may more likely be the result of enhanced (deregulated) biosynthesis rather than inhibited degradation.

An alternative hypothesis to explain the accumulation of citric acid is associated to tricarboxylate transporter activity (38), which competes with aconitase for citric acid. Under conditions in which its affinity for citric acid is greater than that of aconitase, this enzyme ejects citric acid out of the mitochondria without inhibition of enzymes of the cycle.

Finally, there are three different isozymes of isocitrate dehydrogenase in A. niger, a $\mathrm{NAD}^{+}$-dependent form present in mitochondria at low concentrations, and two $\mathrm{NADP}^{+}$dependent forms, one in the mitochondria and the other in the cytoplasm $(40,51)$. All require $\mathrm{Mg}^{2+}$ or $\mathrm{Mn}^{2+}$ and the $\mathrm{NADP}^{+}-$ dependent form is inhibited by citric and $\alpha$-ketoglutaric acids $(40,61)$, which ensures the accumulation of citric acid.

\section{INDUSTRIAL PRODUCTION OF CITRIC ACID}

About $99 \%$ of world production of citric acid occurs via microbial processes, which can be carried out using surface or submerged cultures. The product is sold as an anhydrous or monohydrate acid, and about $70 \%$ of total production of 1.5 million tons per year (52) is used in food and beverage industry as an acidifier or antioxidant to preserve or enhance the flavors and aromas of fruit juices, ice cream, and marmalades. $20 \%$ is used, as such, in the pharmaceutical industry as antioxidant to preserve vitamins, effervescent, $\mathrm{pH}$ corrector, blood preservative, or in the form of iron citrate as a source of iron for the body as well as in tablets, ointments and cosmetic preparations. In the chemical industry, which uses the remaining $10 \%$, is employed as a foaming agent for the softening and treatment of textiles. In metallurgy, certain metals are utilized in the form of citrate. Citric acid is also used in the detergent industry as a phosphate substitute, because of less eutrophic effect, and in the cement one to slow down the hardening of cement.

Although many strains of bacteria produce citric acid, only a few mutants of $A$. niger and $A$. wentii, which are closely related species, are used for industrial production.

All enzymes are expressed during the idiophase, except $\alpha$ ketoglutarate dehydrogenase. The activity of citrate synthase increases by 10 times, whereas those of the aconitase and isocitrate dehydrogenase are reduced slightly compared to the trophophase. During the trophophase, glucose is mainly used for biomass production and oxidized to $\mathrm{CO}_{2}$ via respiration, whereas during the idiophase losses by breath are minimal and the substrate is almost entirely converted to organic acids.

The carbon sources employed in industrial fermentation are sugars in solutions at concentrations ranging from 15 to $25 \%$. Since the microorganisms used industrially have amylases and invertases, which make them capable of hydrolyzing polysaccharides and sucrose, simultaneous saccharification and fermentation processes can be carried out (2) using as substrates potato starch, sugarcane and sugarbeet molasses, among other residues (7). If glucidic hydrolysates are used as culture medium, a pretreatment with precipitating agents or ion exchange resins is necessary to remove cations and then promote the metabolic dysfunction responsible for citric acid accumulation. Alternatively, molasses are often treated with calcium hexacyanoferrate to precipitate heavy metals.

Strains are selected according to the carbon source. To evaluate the optimal cultivation conditions for molasses, no general methods of analysis have been developed; hence, any work cycle should be preceded by a preliminary test of fermentation. Companies using molasses often optimize fermentation conditions in $30 \mathrm{~m}^{3}$ pilot plant before moving to production.

Yields can be maximized using $\mathrm{Cu}^{2+}, \mathrm{Mg}^{2+}, \mathrm{Mn}^{2+}, \mathrm{Fe}^{2+}$, $\mathrm{Zn}^{2+}$ and $\mathrm{Mo}^{2+}$ ions in concentrations in the order of $\mathrm{ppm}$, above which the process is negatively affected. For instance, iron, one of the cofactors of aconitase, plays a crucial role, favoring biomass growth at concentrations higher than $2 \mathrm{ppm}$, or citric acid overproduction at concentrations of only $0.05-0.5$ 
ppm depending on the substrate. Interestingly, $\mathrm{Cu}$ reverses the effect of Fe. Anyhow, sensitivity of microorganisms decreases with decreasing temperature.

$\mathrm{pH}$ is another crucial parameter, which is set at around 5 at the beginning of the trophophase, drops to 3 within the first 48 $\mathrm{h}$ of trophophase as a result of the nitrogen metabolism, and is then kept at this value during the idiophase to inhibit the formation of oxalic and gluconic acids.

\section{Surface cultures}

Citric acid can be produced in surface or submerged cultures. The simple surface culture methods used during the first commercial production required intensive labor. Although submerged culture techniques were developed before 1940, some plants of the first type are apparently still working (62).

According to the substrate employed, surface methods are divided into solids and liquids, the latter being of higher economic importance.

Surface liquid cultures are usually carried out batchwise, using fermentation broths prepared from wheat bran, potato starch, glucose syrup or molasses in concentrations around 160 g/l. With this technology A. niger strains are less sensitive to oligoelements. The first attempts were made using surface liquid nutrients that still provide $20 \%$ of world production, even by some major producers of citric acid (39). Despite these plants being less sensitive to interference by trace metal ions and variations in the dissolved oxygen tension and requiring low capital investment, low energy for cooling and relatively simple technology (39), their maintenance cost is higher, compared to submerged processes, due to the heavy labor required for cleaning pipes, trays and reactor walls.

After steam sterilization, the nutrient medium contained in aluminum trays to a depth of 3-200 cm, depending on their size $(39,59)$, is inoculated at $30-40{ }^{\circ} \mathrm{C}$ by injecting $2-5 \cdot 10^{7}$ dry spores $/ \mathrm{m}^{2}$ or by spraying a spore suspension, and is then incubated at $28-30{ }^{\circ} \mathrm{C}$ (60). 24 hours after inoculation, germinated spores form a continuous mycelium on the surface and $\mathrm{pH}$ drops from 6.0-6.5 to 1.5-2.0. Temperature is usually maintained constant by a stream of sterile air, since avoiding contamination is particularly important in surface fermentations. Such a ventilation is also important to remove $\mathrm{CO}_{2}$, which otherwise would inhibit the production of citric acid in concentrations higher than $10 \%$ while nutrient solutions are sparged through a distribution system on trays. To accelerate the growth, $\alpha$-amylase can be added, even though it is not strictly necessary.

The idiophase begins after about 30 hours. If too much iron is present, recovery can be hampered due to the formation of oxalic acid and yellow pigments. Temperature is kept constant thanks to the evaporation of the solvent and the volume is reduced by $30-40 \%$. The total duration of the cycle is 7-15 days (39) and the daily production 1.2-1.5 kg citric acid monohydrate $/ \mathrm{m}^{2}$, which corresponds to a yield of $70-80 \%$, while heat release is $12,500 \mathrm{~kJ} / \mathrm{g}$ product (60). For recovery, the mycelium must be washed thoroughly with boiling water and eventually pressed.

\section{Submerged cultures}

The industrial production of citric acid in submerged culture was already reviewed in detail $(14,39,59,60)$. Depending on the type of agitation, submerged processes (74) can be divided in mechanically mixed or agitated by air circulation. Most of them are carried out batchwise in conventional or airlift fermenters with $120-250 \mathrm{~m}^{3}$ or $900 \mathrm{~m}^{3}$ volume, respectively.

Spores germinate at $32{ }^{\circ} \mathrm{C}$ in a prefermenter, using a molasses solutions containing $150 \mathrm{~g} / \mathrm{l}$ of sugar in the presence of cyanide ions to induce the formation of mycelium in granular form. Addition of cyanide in insufficient amount favors biomass growth, but affects the subsequent production of citric acid. Granules with 0.2-0.5 mm diameter are formed within 24 hours and then used for the inoculum $(10 \% \mathrm{v} / \mathrm{v})$; after this period the $\mathrm{pH}$ drops to $4.3(29,60)$.

The mode of production of spores and the morphology of the mycelium during the trophophase largely influence the conversion rate, the efficiency and then the success of the process. If the mycelium is thin and wiry, with few branches and no chlamydospores, citric acid is hardly produced during 
idiophase. Pellets of sufficient consistency (1 $\mathrm{mm}$ in diameter) must be formed to increase citric acid production, and this can be done acting also on the $\mathrm{Fe} / \mathrm{Cu}$ ratio in the culture medium.

$80 \%$ of world production of citric acid is obtained by submerged cultures, which have the advantage of lower investment and maintenance costs compared with surface cultures. The disadvantages are the high cost of energy and a more sophisticated technology, which in turn requires specialized staff. The main substrates are solutions of sucrose, molasses or glucose from cornstarch with $160 \mathrm{~g} / \mathrm{l}$ of total sugars, $25 \%$ of which are consumed during the trophophase (pH 5 and duration of 20-40 h) and 75\% during the idiophase ( $\mathrm{pH}$ 2-3 and duration of 4-6 days). For best control, the two phases can be separated by lowering the $\mathrm{pH}$ below 2 after the end of growth. Another advantage of the strong acidity is the low risk of contamination.

Two additional factors are of particular importance for citric acid production in submerged cultures: the type of material used to build the fermenter and the aeration. Fermenters must be resistant to acidity and are made of stainless steel, because ordinary steel can be dissolved at $\mathrm{pH}$ 12 , inhibiting the fermentation. In fermenters with capacity less than $1 \mathrm{~m}^{3}$, due to increased surface/volume ratio, corrosion becomes significant, and even steel chambers must be protected with a layer of plastic material.

Because A. niger is quite unstable genetically, only a small number of stages can be used for the development of the inoculums, and in some applications the spores are even inoculated directly into the fermenter. A. niger requires relatively little oxygen, but it is very sensitive to its total absence, and even brief interruptions can cause an immediate cessation of production. A rate of aeration of $0.2-1 \mathrm{vvm}$ is often used during the production phase to avoid dissolved oxygen levels lower than $20-25 \%$ of the saturation concentration. Thanks to the low viscosity of cultures, in some cases no mechanical agitation is used or airlift reactors are employed.

Compared with surface cultures, submerged cultures are somewhat less sensitive to changes in the composition of media, which is an advantage when using molasses having a highly variable composition. On the other hand, a typical problem of submerged cultures is the formation of foam, which can be avoided using antifoam agents and chambers with volume of up to one third of the total fermenter volume. The most common antifoams are animal or vegetable fats or mechanical systems. The final yield after 7 to 10 days is $70-$ $90 \%$, corresponding to $110-140 \mathrm{~g} / 1$ of citric acid and 10-15 g/l of dry biomass $(39,60)$.

\section{Process with yeasts from hydrocarbons}

In addition to $A$. niger, several yeasts, among which Candida catenula, Candida guilliermondii, Yarrowia lipolytica and Candida tropicalis, have been described that form large amounts of citric acid from $n$-alkanes or -even though with lower yield- from glucose (39). When this process was successfully used before the world oil crisis of 1973/1974, the culture medium usually consisted of C9-C23n-akanes in a concentration of $100 \mathrm{~g} / \mathrm{l}$, and the best results were obtained with $Y$. lipolytica in batch (duration of 5-6 days) or fed-batch submerged systems at $\mathrm{pH}$ 5.0-6.5 and 1.0-1.5 vvm aeration (60). The yield is higher than with carbohydrates (1.30-1.45 grams of acid per gram of paraffin) (14), but there are difficulties associated with low water solubility of alkanes and the presence of up to $50 \%$ of isocitric acid among the products, which has to be separated during recovery (59). Therefore, mutants with very low aconitase activity were selected using monofluoroacetate resistance as a selection criterion (39).

\section{BIOPRODUCTION OF CITRIC ACID FROM INDUSTRIAL BY-PRODUCTS}

Its low cost, high carbohydrate content and high susceptibility to fermentation make the processing of citrus byproducts an attractive, environmentally-friendly, alternative way for the biotechnological production of chemicals (23).

The recombinant strain Escherichia coli KO11 was shown to ferment arabinose and galacturonic acid obtained from enzymatic hydrolysates of orange peel to acetic acid, ethanol, carbon dioxide and small amounts of lactic acid $(10,72)$. Due 
to the presence of inhibitors such as limonene, the fermentation of these hydrolysates by the yeast Saccharomyces cerevisiae did not give interesting results $(53,54,70,98,105)$. After removal by filtration, the yeast was shown to ferment well only hexoses such as glucose, fructose and galactose released by enzymatic hydrolysis of the polysaccharides contained in the peel (22), but not pentoses (arabinose and xylose) or galacturonic acid (96).

Liquors extracted from orange peel have been used as substrates for citric acid production by fungi (12, 50). Aravantinos-Zafiris et al. (5) utilized to this purpose three different, commercially-available strains of A. niger, specifically NRRL 599, 364 and 567, being the first one the best producer of citric acid. The most favorable conditions for citric acid production by $A$ niger NRRL 599 resulted to be $\mathrm{pH}$ 5.8 in the presence of $40 \mathrm{ml} / \mathrm{kg}$ of methanol, without additional nutrients. Under these conditions, the concentration of citric acid after 12 days was $30 \mathrm{~g}$ of citric acid per $\mathrm{kg}$ of liquor from orange peels washing, corresponding to a yield of $630 \mathrm{~g} / \mathrm{kg}$ based on total sugars consumed. The yield increased up to 730 $\mathrm{g} / \mathrm{kg}$ when the liquor was previously subjected to a thermal pretreatment.

The yields obtained with this substrate are comparable or even higher than those obtained using other raw materials such as oil, starch and molasses (95). These authors reported a citric acid concentration of $27 \mathrm{~g} / \mathrm{l}$ with a yield of $45 \%$ when using wood hemicelluloses hydrolysates, while Adham (1) reached a maximum concentration of $8.6 \mathrm{~g} / \mathrm{l}$ (9.8\% conversion) using beet molasses.

Zhang (111) used solid wastes from a factory producing orange juice as a substrate for citric acid production by A. niger 999. It was necessary to add again $2 \%$ of methanol to the culture broth, and the fermentation lasted 4 days at $30^{\circ} \mathrm{C}$. Kang et al. (33) produced citric acid from tangerine skins using $A$. niger, finding the highest production in semisolid state cultures. Furthermore, the production of citric acid was enhanced by the addition of $0.2 \% \quad \mathrm{NH}_{4} \mathrm{NO}_{3}, 0.1 \%$ of $\mathrm{MgSO}_{4} .7 \mathrm{H}_{2} \mathrm{O}, 2.5 \%$ methanol or $1.5 \%$ of ethanol. Under optimal conditions, the maximum yield of citric acid was
$80.4 \%$ of the theoretical value.

Kumagai et al. (47), who studied the factors influencing the semisolid citric acid production by A. niger from dry and concentrated liquid tangerine wastes, found that the fermentation of the former residue required the addition of molasses juice to face the negative effect of large amounts of impurities. Thus, the maximum concentration of citric acid was achieved in a medium consisting of $6 \mathrm{~g}$ of tangerine skin and $11 \mathrm{ml}$ molasses juice (14\% sugar content) that ensured fermentation yields in the range $55-65 \%$ at $30^{\circ} \mathrm{C}$ after 3 days. Hang et al. (27), using the skin of kiwi and A. niger NRRL 567 , produced about 100 grams of citric acid/kg in the presence of $2 \%$ methanol at $30^{\circ} \mathrm{C}$ after 4 day-solid-state fermentation, with a yield higher than $60 \%$ based on consumed sugars.

Vandenberghe et al. (104), who evaluated three different agro-industrial wastes, specifically sugarcane bagasse, coffee husk and cassava bagasse, to produce citric acid by a culture of Aspergillus niger, found the highest CA yield (88 g/kg dry matter) when the fermentation was carried out with cassava bagasse as a substrate. Finally, Flores et al. (20), after 5 daysolid-state fermentation of dry prickly pear skin by A. niger, achieved a maximum production of $380 \mathrm{~g}$ of monohydrate CA per $\mathrm{kg}$ at $30{ }^{\circ} \mathrm{C}$ and $86 \%$ humidity, corresponding to a yield on initial sugars of $68 \%$ and to a maximum volumetric productivity of $0.539 \mathrm{~g} / \mathrm{lh}$.

Methanol can stimulate citric acid fermentation. Wastes from pineapple shells were also used to produce citric acid by A. niger ATCC 1015 (57). The highest production (132 g/kg of residue) was achieved after 6 days of fermentation at $29^{\circ} \mathrm{C}$ in medium containing $4 \%$ methanol. This residue was also employed by Tran et al. (102) with three strains of A. niger and Aspergillus foetidus. Among these, A. niger ACM 4992 ensured the highest citric acid production (194 g/kg), corresponding to a yield of $0.74 \mathrm{~g}$ citric acid/g sugar consumed. The optimal conditions were $65 \%$ initial moisture, $3 \%$ methanol, $30{ }^{\circ} \mathrm{C}$, unadjusted initial $\mathrm{pH}$ of 3.4, a particle size of $2 \mathrm{~mm}$ and $5 \mathrm{ppm}$ of $\mathrm{Fe}^{2+}$. Citric acid production was carried out more effectively by using Erlenmeyer flasks in batch fermentations, while yields decreased when trays or rotating 
drums bioreactors were used. The same stimulating effect of methanol was observed by Kumar et al. (48, 49) using a mixture of different fruit wastes and bagasse for A. niger DS1 solid-state fermentation. The use of $4 \%$ methanol (v/w) was also reported for the submerged fermentation of orange peel hydrolysates (84) and the solid-state fermentation of sugarcane molasses (85), that led to citric acid productions of $9.2 \mathrm{~g} / \mathrm{l}$ and $445.4 \mathrm{~g} / \mathrm{kg}$, respectively. Roukas (88) observed an increase in citric production from 176 to $264 \mathrm{~g} / \mathrm{kg}$ when the concentration of methanol was increased up to $6 \%(\mathrm{w} / \mathrm{w})$ in dry pod solidstate fermentation. Although the role of methanol stimulation is not completely known, it was related to a) removal of the adverse effect of trace metals (84), b) changes in the mycelium morphology consequent to variations in phospholipid composition (83), c) increase in cell membrane permeability, thereby making the excretion of citric acid easier (111), or d) some influence on growth and sporulation (31).

Conversely, some authors observed detrimental effects when methanol was added, since the microorganism is not able to assimilate it. For instance, CA production by solid-state fermentation of kiwifruit peel by A. niger ATCC 9142 significantly decreased after supplementation with $0.74 \mathrm{mmol}$ methanol/l (27), and Tsay and To (103) reported that methanol inhibited both A. niger TMB 2022 growth and CA production. Similar findings were reported by other authors $(4,71,109)$.

\section{CITRIC ACID RECOVERY}

The first step of citric acid recovery involves the precipitation of oxalic acid, possibly in the form of calcium oxalate at low $\mathrm{pH}$, and subsequent separation from the medium containing the mycelium through rotating filters or centrifuges. Citric acid is then precipitated at $\mathrm{pH} 7.2$ and $70-90{ }^{\circ} \mathrm{C}$ and recovered by filtration and drying. If a purer product were desired, it is dissolved with sulfuric acid, treated with charcoal or ion exchange resins, and again crystallized as anhydrous citric acid (above $40{ }^{\circ} \mathrm{C}$ ) or as a monohydrate (below $36.5^{\circ} \mathrm{C}$ ) (60). In surface processes, the mycelium is sometimes squeezed to increase the recovery yield.
Pinacci and Radaelli (82) have proposed a process of electrodialysis with bipolar membranes for the recovery of citric acid from fermentation media, while Kılıç et al. (34) an extractive fermentation, in which the steps of citric acid production by $A$. niger and separation occur simultaneously, using corn oil and Hostarex A327 in oleic alcohol.

In the process carried out with $Y$. lipolytica, the recovery of citric acid after filtration of the exhausted medium includes the precipitation of oxalic acid at low $\mathrm{pH}$ in form of calcium salt followed by citric acid precipitation at $\mathrm{pH} 7.2$ and 70-90 ${ }^{\circ} \mathrm{C}$.

\section{REFERENCES}

1. Adham, N.Z. (2002). Attempts at improving citric acid fermentation by Aspergillus niger in beet-molasses medium. Bioresour Technol. 84, 97100 .

2. Aghdam, M.G.; Taherzadeh, M. (2008). Production of citric acid by solid state fermentation. J Biotechnol. 136, S464.

3. Ahmed, S.A.; Smith, J.E.; Anderson, J.A. (1972). Mitochondrial activity during citric acid production by Aspergillus niger. Trans. Br. Mycol. Soc. $59,51-61$

4. Ali, S.; Ashraf, H.; Ikram, U. (2002). Enhancement in citrate production by alcoholic limitation. J. Biol. Sci. 2, 70-72.

5. Aravantinos-Zafiris, G.; Tzia, C.; Oreopoulou, V.; Thomopoulos, C. D. (1994). Fermentation of orange processing wastes for citric acid production. J. Sci. Food Agric. 65, 117-120.

6. Arts, E.; Kubicek, C.; Röhr, M. (1987). Regulation of phosphofructokinase from Aspergillus niger: effect of fructose-2,6bisphosphate on the action of citrate, ammonium ions and AMP. J. Gen. Microbiol. 133, 1195-1199.

7. Bizukojc, M.; Ledakowicz, S. (2004). The kinetics of simultaneous glucose and fructose uptake and product formation by Aspergillus niger in citric acid fermentation. Proc. Biochem. 39, 2261-2268.

8. Bloom, S.J.; Johnson, M.J. (1962). The pyruvate carboxylase of Aspergillus niger. J. Biol. Chem. 237, 2718-2720.

9. Boddy, L.M.; Berges, T.; Barreau, C.; Vainstain, M.H.; Johnson, M.J.; Ballance, D.J.; Peberdi, J.F. (1993). Purification and characterisation of an Aspergillus niger invertase and its DNA sequence. Curr. Genet. 24, 60-66.

10. Burchhardt, G.; Ingram, L.O. (1992). Conversion of xylan to ethanol by ethanologenic strains of Escherichia coli and Klebsiella oxytoca. Appl. Environ. Microb. 58 (4), 1128-1133

11. Clark, D.S.; Ito, K.; Horitsu, H. (1966). Effect of manganese and other heavy metals on submerged citric acid fermentation of molasses. 
Biotechnol. Bioeng. 8, 465-471.

12. Clark, D.S.; Lentz, C.P. (1961). Submerged citric acid fermentation of sugar beet molasses: effect of pressure and recirculation of oxygen. Can. J. Microbiol. 7, 447-445.

13. Cleland, W.W.; Johnson, M.J. (1954). Tracer experiments on the mechanism of citric acid formation by Aspergillus niger. J. Biol. Chem. 208, 679-692.

14. Converti, A. (2009). Aprovechamiento de residuos agroindustriales para la generación de aditivos alimentarios: Tratamiento de las materias primas y estudios metabólicos. Vigo, Spain, 240p. (PhD Dissertation. Faculty of Sciences. Vigo University).

15. Currie, J.N. (1917). The citric acid fermentation of A. niger. J. Biol. Chem. 31, 5 .

16. De Graaff, L.; van den Broeck, H.; Visser, J. (1988). Isolation and characterisation of the pyruvate kinase gene of Aspergillus nidulans. Curr. Genet. 13, 315-321.

17. De Graaff, L.; van den Broeck, H.; Visser, J. (1992). Isolation and characterisation of the Aspergillus niger pyruvate kinase gene. Curr. Genet. 22, 21-27.

18. Dronawat, S.N.; Svihla, C.K.; Hanley, T.R. (1995). The effects of agitation and aeration on the production of gluconic acid by Aspergillus niger. Appl. Biochem. Biotechnol. 51/52, 347-354.

19. Feir, H.A.; Suzuki, I. (1969). Pyruvate carboxylase of Aspergillus niger: kinetic study of a biotin-containing enzyme. Can. J. Biochem. 47, 697710.

20. Flores, J.L.; Gutierrez-Correa, M.; Tengerdy, R.P. (1994). Citric acid production by solid state fermentation of prickly pear peel with Aspergillus niger. Agro-Food-Industry Hi-Tech 5(1), 18-20.

21. Grimoux, E.; Adams, P. (1880). Synthese de lácide citrique. C. R. Hebd. Seances Acad. Sci. 90, 1252.

22. Grohmann, K.; Cameron, R.G.; Buslig, B.S. (1995). Fermentation of sugars in orange peel hydrolyzates to ethanol by recombinant Escherichia coli KO11. Appl. Biochem. Biotechnol. 51/52, 423-35.

23. Grohmann, K.; Cameron, R.G.; Buslig, B.S. (1995). Fractionation and pretreatment of orange peel by dilute acid hydrolysis. Bioresour Technol. $54,129-141$.

24. Gupta, J.K.; Heding, L.G.; Jorgensen, O.B. (1976). Effect of sugars, hydrogen ion concentration and ammonium nitrate on the formation of citric acid by Aspergillus niger. Acta Microbiol. Acad. Sci. Hung 23, 6367.

25. Habison, A.; Kubicek, C.P.; Röhr, M. (1979). Phosphofructokinase as a regulatory enzyme in citric acid accumulating Aspergillus niger. FEMS Microbiol. Lett. 5, 39-42.

26. Habison, A.; Kubicek, C.P.; Röhr, M. (1983). Partial purification and regulatory properties of phosphofructokinase from Aspergillus niger. Biochem. J. 209, 669-676.

27. Hang, Y.D.; Luh, B.S.; Woodams, E.E. (1987). Microbial production of citric acid by solid state fermentation of kiwifruit peel. J. Food Sci. 52, 226-227.
28. Hayashi, S.; Nakamura, S. (1981). Multiple forms of glucose oxidase with different carbohydrate compositions. Biochim. Biophys. Acta 657, $40-51$.

29. Honecker, S.; Bisping, B.; Yang, Z.; Rehm, H.J. (1989). Influence of sucrose concentration and phosphate limitation on citric acid production by immobilized cells of Aspergillus niger. Appl. Microbiol. Biotechnol. $31,17-24$

30. Hossain, M.; Brooks, J.D.; Maddox, I.S. (1984). The effect of the sugar source on citric acid production by Aspergillus niger. Appl. Microbiol. Biotechnol. 19, 393-397.

31. Ingram, L.O.; Buttke, T.M. (1984). Effects of alcohols on microorganisms. Adv. Microb. Physiol. 25, 253.

32. Jernejc, K.; Perdih, A.; Cimerman, A. (1992). Biochemical composition of Aspergillus niger mycelium grown in citric acid productive and nonproductive conditions. J. Biotechnol. 25, 341-348.

33. Kang, S.K.; Park, H.H.; Lee, J.H.; Lee,Y.S.; Kwon, I.B.; Sung, N.K. (1989). Citric acid fermentation from mandarin orange peel by Aspergillus niger. Sanop. Misaengmul Hakhoechi 17, 510-518.

34. Kılıç, M.; Bayraktar, E.; Ate, S.; Mehmetoglu, Ü. (2002). Investigation of extractive citric acid fermentation using response-surface methodology. Proc. Biochem. 37, 759-767.

35. Kisser, M.; Kubicek, C.P.; Röhr, M. (1980). Influence of manganese and cell wall composition of Aspergillus niger during citric acid fermentation. Arch. Microbiol. 128, 26-33.

36. Kristiansen, B.; Sinclair, C.G. (1978). Production of citric acid in batch culture. Biotechnol. Bioeng. 20, 1711-1722.

37. Kristiansen, B.; Sinclair, C.G. (1979). Production of citric acid in continuous culture. Biotechnol. Bioeng. 21, 297-315.

38. Kubicek C.P., The role of the citric acid cycle in fungal organic acid fermentations, Biochem Soc Symp 54 (1987) 113-126.

39. Kubicek, C.P. (2001). Organic acids. In: Ratledge, C.; Kristiansen, B. (eds.), $2^{\text {nd }}$ Edition, Chapt. 14. Basic Biotechnology. Cambridge, UK. Cambridge University Press, pp. 305-324.

40. Kubicek, C.P.; Röhr, M. (1977). Influence of manganese on enzyme synthesis and citric acid accumulation in Aspergillus niger. Appl. Microbiol. Biotechnol. 4, 167-175.

41. Kubicek, C.P.; Röhr, M. (1980). Regulation of citrate synthase from the citric acid producing fungus Aspergillus niger. Biochim. Biophys. Acta 615, 449-457.

42. Kubicek, C.P.; Röhr, M. (1989). Citric acid fermentation. Crit. Rev. Biotechnol. 4, 331-373.

43. Kubicek, C.P.; Schreferl-Kunar, G.; Wöhrer, W.; Röhr, M. (1988). Evidence for a cytoplasmic pathway of oxalate biosynthesis in Aspergillus niger. Appl. Environ. Microbiol. 54, 633-637.

44. Kubicek, C.P.; Zehentgruber, O.; El-Kalak , H.; Röhr, M. (1980). Regulation of citric acid production by oxygen: effects of dissolved oxygen tension on adenylate levels and respiration in Aspergillus niger. Eur. J. Appl. Microbiol. Biotechnol. 9, 101-116.

45. Kubicek, C.P.; Zehentgruber, P.; Röhr, M. (1979). An indirect method 
for studying fine control of citric acid accumulation by Aspergillus niger. Biotechnol. Lett. 1, 47-52.

46. Kubicek-Pranz, E.M.; Mozelt, M.; Röhr, M.; Kubicek, C.P. (1990). Changes in the concentration of fructose 2,6-bisphosphate in Aspergillus niger during stimulation of acidogenesis by elevated sucrose concentration. Biochim. Biophys. Acta 1033, 250-255.

47. Kumagai, K.; Usami, S.; Hattori, S. (1981). Citric acid production from mandarin orange waste by solid culture of Aspergillus niger. Hakko Kogaku Kaishi 59(5), 461-464.

48. Kumar, D.; Jain, V.K.; Shanker, G.; Srivastava, A. (2003). Citric acid production by solid state fermentation using sugarcane bagasse. Proc. Biochem. 38, 1731-1738.

49. Kumar, D.; Jain, V.K.; Shanker, G.; Srivastava, A. (2003). Utilisation of fruits waste for citric acid production by solid state fermentation. Proc. Biochem. 38, 1725-1729.

50. Kundu, S.; Panda, T.; Majumdar, S.K.; Guha, B.; Bandyopadhyay, K.K. (1984). Pretreatment of Indian cane molasses for increased production of citric acid. Biotechnol. Bioeng. 26(9), 1114-1121.

51. LaNauze, J.M. (1966). Aconitase and citric acid dehydrogenases in Aspergillus niger in relation to citric acid accumulation. J. Gen. Microbiol. 44, 73-81.

52. Lancini, G. (2008). Parte I - L'uso industriale dei microrganismi. Storia e campi di applicazione. In: Donadio, S.; Marino, G. (eds.). Biotecnologie Microbiche, Casa Editrice Ambrosiana, Milan, p. 5-35.

53. Lane A G. (1980). Production of aromatic acids during anaerobic digestion of citrus peel. J. Chem. Technol. Biot. 30(6), 345-50.

54. Lane A G. (1983). Removal of peel oil from citrus peel press liquors before anaerobic digestion. Environ. Tech. Lett. 4(2), 65-72.

55. Legiša, M.; Benčina, M. (1994). Evidence for the activation of 6phosphofructo-1-kinase by cAMP-dependent protein kinase in Aspergillus niger. FEMS Microbiol. Lett. 118, 327-334.

56. Legiša, M.; Mattey, M. (1986). Glycerol as an initiator of citric acid accumulation in Aspergillus niger. Enzyme Microb. Technol. 8, 607-609.

57. Lima, V.L.A.G.; Stamford, T.L.M.; Salgueiro, A.A. (1995). Citric acid production from pineapple waste by solid-state fermentation using Aspergillus niger. Arq. Biol. Technol. 38, 773-783.

58. Lowenstein, J.M. (1969). Citric Acid Cycle - Control and Compartmentation, Dekker, London.

59. Manzoni, M. (2006). Microbiologia Industriale, $1^{\text {th }}$ Edn., Casa Editrice Ambrosiana, Milán.

60. Marzona, M. (1996). Chimica delle Fermentazioni \& Microbiologia Industriale, $2^{\text {nd }}$ Edn., Piccin, Padua, Italia.

61. Mattey, M. (1977). Citrate regulation of citric acid production by Aspergillus niger. FEMS Microbiol. Lett. 2, 71-74.

62. Mattey, M. (1992). The production of organic acids, Crit Rev Biotechnol. $12,87-132$.

63. Mattey, M. (1999). Biochemistry of citric acid production by yeasts. In: Kristiansen, B., Mattey, M., Linden, J. (eds). Citric Acid Biotechnology,
Taylor and Francis, London, p. 33-54.

64. Mattey, M.; Bowes, I. (1978). Citrate regulation of $\mathrm{NADP}^{+}$-specific isocitrate dehydrogenase of Aspergillus niger. Biochem. Soc. Trans. 6, 1224-1226.

65. McIntyre, M.; McNeil, B. (1997). Dissolved carbon dioxide effects on morphology, growth and citrate production in Aspergillus niger A60. Enzyme Microb. Technol. 20, 135-142.

66. Meixner-Monori, B.; Kubicek, C.P.; Röhr, M. (1984). Pyruvate kinase from Aspergillus niger: a regulatory enzyme in glycolysis?. Can. J. Microbiol. 30, 16-22.

67. Mischak, H.; Kubicek, C.P.; Röhr, M. (1985). Formation and location of glucose oxidase in citric acid producing mycelia of Aspergillus niger. Appl. Microbiol. Biotechnol. 21, 27-31.

68. Moyer, A.J. (1953). Effect of alcohol on the mycological production of citric acid in surface and submerged culture, I, Nature of the alcohol effect. Appl. Microbiol. 1, 1-7.

69. Müller, H.M. (1975). Oxalate accumulation from citrate by Aspergillus niger. I. Biosynthesis of oxalate from its ultimate precursor. Arch. Microbiol. 103, 185-189.

70. Murdock, D.I.; Allen, W.E. (1960). Germicidal effect of orange peel oil and d-limonene in water and orange juice I. Fungicide properties against yeast. Food Technol-Chicago 14(9), 441-445.

71. Navaratnam, P.; Arasaratnam, V.; Balasubramaniam, K. (1998). Channelling of glucose by methanol for citric acid production from Aspergillus niger. World J. Microbiol. Biotechnol. 14(4), 559-563.

72. Ohta, K.; Beall, D.S.; Mejía, J.P.; Shanmugam, K.T.; Ingram, L.O. (1991). Genetic improvement of Escherichia coli for ethanol production: chromosomal integration of Zymomonas mobilis genes encoding pyruvate decarboxylase and alcohol dehydrogenase II. Appl. Environ. Microb. 57(4), 893-900.

73. Papagianni, M. (2007). Advances in citric acid fermentation by Aspergillus niger: Biochemical aspects, membrane transport and modeling. Biotechnol. Adv. 25, 244-263.

74. Papagianni, M.; Mattey, M. (2004). Modeling the mechanisms of glucose transport through the cell membrane of Aspergillus niger in submerged citric acid fermentation processes. Biochem. Eng. J. 20, 7-12.

75. Papagianni, M.; Mattey, M. (2006). Morphological development of Aspergillus niger in submerged citric acid fermentation as a function of the spore inoculum level. Application of neural network and cluster analysis for characterization of fungal morphology. Microbial Cell Factories 5, 3 .

76. Papagianni, M.; Mattey, M.; Berovic, M.; Kristiansen, B. (1999). Aspergillus niger morphology and citric acid production in submerged batch fermentation: effects of culture $\mathrm{pH}$, phosphate and manganese levels. Food Technol. Biotechnol. 37, 165-171.

77. Papagianni, M.; Mattey, M.; Kristiansen, B. (1998). Citric acid production and morphology of Aspergillus niger as functions of the mixing intensity in a stirred tank and a tubular loop bioreactor. Biochem. 
Eng. J. 2, 197-205.

78. Papagianni, M.; Mattey, M.; Kristiansen, B. (1994). Morphology and citric acid production of Aspergillus niger PM1. Biotechnol. Lett. 16, 929-934.

79. Papagianni, M.; Mattey, M.; Kristiansen, B. (1999). Hyphal vacuolation and fragmentation in batch and fed-batch culture of Aspergillus niger and its relation to citric acid production. Process Biochem. 35, 359-366.

80. Papagianni, M.; Mattey, M.; Kristiansen, B. (1999). The influence of glucose concentration on citric acid production and morphology of Aspergillus niger in batch and fed-batch culture. Enzyme Microb. Technol. 25, 710-717.

81. Papagianni, M.; Wayman, F.M.; Mattey, M. (2005). Fate and role of ammonium ions during fermentation of citric acid by Aspergillus niger. Appl. Environ. Microbiol. 71, 7178-7186.

82. Pinacci, P.; Radaelli, M. (2002). Recovery of citric acid from fermentation broths by electrodialysis with bipolar membranes. Desalination 148, 177-179.

83. Pintado, J.; Torrado, A.; Miron, J.; Montemayor, I.; Gonzalez, P.; Murado, M.; Sanroman, A. (1995). Citric acid production from mussel processing wastes in solid state culture. Mededelingen - Faculteit Landbouwkundige en Toegepaste Biologische Wetenschappen (Universiteit Gent) 59(4B), 2429-37.

84. Rivas, B.; Torrado, A.; Torre, P.; Converti, A.; Domínguez, J.M. (2008). Submerged citric acid fermentation on orange peel autohydrolysate. $J$. Agric. Food Chem. 56, 2380-2387.

85. Rodrigues, C.; De Souza Vandenberghe, L.P.; Teodoro, J.; Pandey, A.; Soccol, C.R. (2009). Improvement on Citric Acid Production in Solidstate Fermentation by Aspergillus niger LPB BC Mutant Using Citric Pulp. Appl. Biochem. Biotechnol. 158, 72-87.

86. Rogalski, J.; Fiedureck, J.; Szczodrak, J.; Kapusta, K.; Leonowicz, A. (1988). Optimisation of glucose oxidase synthesis in submerged cultures of Aspergillus niger G-143 mutant. Enzyme Microb. Technol. 10, 508511.

87. Röhr, M.; Kubicek, C.P. (1981). Regulatory aspects of citric acid fermentation by Aspergillus niger. Process Biochem. 16, 34-37.

88. Roukas, T. (1999). Citric acid production from carob pod by solid-state fermentation. Enzyme Microb. Technol. 24, 54-59.

89. Rubio, M.C.; Maldonado, M.C. (1995). Purification and characterisation of invertase from Aspergillus niger. Curr. Microbiol. 31, 80-83.

90. Ruijter, G.J.; Panneman, H.; van den Broeck, H.C.; Bennett, J.M.; Visser, J. (1996). Characterisation of the Aspergillus nidulans fral mutant: hexose phosphorylation and apparent lack of involvement of hexokinase in glucose repression. FEMS Microbiol. Lett. 139, 223-228.

91. Schreferl-Kunar, G.; Grotz, M.; Röhr, M.; Kubicek, C.P. (1989). Increased citric acid production by mutants of Aspergillus niger with increased glycolytic capacity. FEMS Microbiol. Lett. 59, 297-300.

92. Shu, P.; Johnson, M.J. (1948). Citric acid production by submerged fermentation with Aspergillus niger. Ind. Eng. Chem. 40, 1202-1205.

93. Shu, P.; Johnson, M.J. (1948). The interdependence of medium constituents in citric acid production by submerged fermentation. $J$. Bacteriol. 54, 161-167.

94. Snell, R.L.; Schweiger, L.B. (1951). Citric acid by fermentation. British Patent 653 808. Chem Abstr 45 8719a.

95. Soccol, C.R.; Vandenberghe, L.P.S.; Rodrigues, C.; Pandey, A. (2006). New perspectives for citric acid production and application. Food Technol. Biotechnol. 44, 141-149.

96. Stabnikova. O.; Wang, J.-Y.; Ivanov, V. (2010). Value-added biotechnological products from organic wastes. In: Wang, L.-K.; Ivanov, V.; Tay, J.-H.; Hung, Y.-T. (eds.). Environmental Biotechnology, Vol. 10, Humana Press, Totowa-NJ, USA, p. 343-394.

97. Steinböck, F.; Held, I.; Choojun, S.; Röhr, M.; Kubicek, C.P. (1994). Characterization and regulatory properties of a single hexokinase from the citric acid accumulating fungus Aspergillus niger. Biochim. Biophys. Acta 1200, 215-223.

98. Subba M S, Soumithri T C, Rao R S. (1967). Antimicrobial action of citrus oils. Journal of Food Science, 32(2), 225-227.

99. Takahashi, J.; Yamada, K.; Aasai, T. (1958). Studies on the effect of some physical conditions on the submerged mold culture: Part I. The process of pellet formation of Aspergillus niger under the shaking culture, and the effect of the inoculum size on the shape of pellet. $J$. Agric. Chem. Soc. 32, 501-506.

100. Torres, N.V. (1994). Modeling approach to control of carbohydrate metabolism during citric acid production by Aspergillus niger: I. Model definition and stability of the steady state. Biotechnol. Bioeng. 44, 104111.

101. Torres, N.V. (1994). Modeling approach to control of carbohydrate metabolism during citric acid production by Aspergillus niger: II. Sensitivity analysis. Biotechnol. Bioeng. 44, 112-118.

102. Tran, C.T.; Sly, L.I.; Mitchell, D.A. (1998). Selection of a strain of Aspergillus for the production of citric acid from pineapple waste in solid-state fermentation. World J. Microbiol Biotechnol. 14, 399-404.

103. Tsay, S.S.; To, K.Y. (1987). Citric acid production using immobilized conidia of Aspergillus niger TMB 2022. Biotechnol. Bioeng. 19, 297304.

104. Vandenberghe, L.P.S.; Soccol, C.R.; Pandey, A.; Lebeault, J.-M. (2000). Solid-state fermentation for the synthesis of citric acid by Aspergillus niger. Bioresour Technol. 74, 175-178.

105. Von Loesecke, H.W.; Mottern, H.H.; Pulley, G.N. (1934). Preservation of orange juice by deaeration and flash pasteurization. J. Ind. Eng. Chem. $26,771-773$

106. Wehmer, C. (1893). Note sur la fermentation citrique, Bull. Soc. Chem. Fr. 9, 728 .

107. Wongchai, V.; Jefferson, Jr. W.E. (1974). Pyruvate carboxylase from Aspergillus niger: partial purification and some properties. Fed. Proc. 33, 1378.

108. Woronick, C.L.; Johnson, M.J. (1960). Carbon dioxide fixation by cellfree extracts of Aspergillus niger. J. Biol. Chem. 235, 9-15.

109. Xie, G.; West, T.P. (2009). Citric acid production by Aspergillus niger 
110. ATCC 9142 from a treated ethanol fermentation co-product using solidstate fermentation. Lett. Appl. Microbiol. 48, 639-644.

111. Xu, B.D.; Madrit, C.; Röhr, M.; Kubicek, C.P. (1989). The influence of type and concentration of the carbon source on production of citric acid by Aspergillus niger. Appl. Microbiol. Biotechnol. 30, 553-558.
112. Zhang, Q. (1988). Utilization of citrus wastes in production of citric acid. Shipin Kexue (Beijing, China) 104, 21-24. 